\title{
Complications and pitfalls in minimally invasive atrioventricular valve surgery utilizing endo-aortic balloon occlusion technology
}

\author{
Johan van der Merwe, Frank Van Praet, Yvette Vermeulen, Filip Casselman \\ Department of Cardiovascular and Thoracic Surgery, OLV Clinic, Aalst, Belgium \\ Contributions: (I) Conception and design: J van der Merwe, F Van Praet, F Casselman; (II) Administrative support: All authors; (III) Provision of study \\ materials or patients: F Van Praet, Y Vermeulen, F Casselman; (IV) Collection and assembly of data: J van der Merwe, Y Vermeulen, F Casselman; \\ (V) Data analysis and interpretation: J van der Merwe, Y Vermeulen, F Casselman; (VI) Manuscript writing: All authors; (VII) Final approval of \\ manuscript: All authors. \\ Correspondence to: Filip Casselman, MD, PhD, FETCS. Department of Cardiovascular and Thoracic Surgery, OLV Clinic, Moorselbaan 164, 9300 \\ Aalst, Belgium. Email: Filip.Casselman@olvz-aalst.be.
}

Background: This study reports the intra-operative complications, reasons for sternotomy conversion (SC) and the important pitfalls associated with minimally invasive atrioventricular valve surgery by endo-aortic balloon occlusion (MIAS) that may assist emerging centres in developing safe, efficient and sustainable programs.

Methods: Peri-operative data for patients operated over the last 5 years was obtained from a prospective database. In total, 511 consecutive patients with isolated atrioventricular valve (AVV) disease underwent MIAS (mean age $65.6 \pm 13.7$ years, $46.8 \%$ female, $21.7 \%$ redo-cardiac surgery, $5.7 \%$ previous MIAS, $2.9 \%$ isolated AVV endocarditis, $13.9 \%$ body mass index above $30 \mathrm{~kg} / \mathrm{m}^{2}$ ) at our institution between May $1^{\text {st }} 2013$ and April $30^{\text {th }}$ 2018. The mean EuroSCORE II was 5.9\% $9.4 \%$ and rheumatic AVV disease was diagnosed in $32(6.3 \%)$ patients. Other surgical indications included chronic atrial fibrillation $(\mathrm{n}=142,27.8 \%)$ and left ventricle outflow tract (LVOT) obstruction in conjunction with mitral (MV) or tricuspid valve (TV) disease $(\mathrm{n}=7,1.4 \%)$.

Results: Procedures performed included 122 AVV replacements ( $M V=105$, TV =17) and 478 AVV repairs $(\mathrm{MV}=383, \mathrm{TV}=95)$ in isolation or combination. Concomitant procedures included cryo-ablation $(\mathrm{n}=142$, $27.8 \%)$ and LVOT resection $(\mathrm{n}=7,1.4 \%)$. Intra-operative complications that required SC occurred in $16(3.1 \%)$ patients and in 13 of $399(3.3 \%)$ isolated MV procedures. Reasons for SC included lung adhesions $(\mathrm{n}=5,1.0 \%)$, cannulation difficulty $(\mathrm{n}=3,0.6 \%)$, atrioventricular dehiscence $(\mathrm{n}=1,0.2 \%)$ and bleeding $(n=4,0.8 \%)$. Other peri-operative complications included neurological deficit $(n=2,0.4 \%)$ and myocardial infarction ( $\mathrm{n}=1,0.2 \%)$. The intra-operative and 30-day mortality for the 5-year MIAS series ( $\mathrm{n}=511)$ was $0.4 \%$ $(n=2)$ and $4.5 \%(n=23)$ respectively. Complications that resulted in SC $(n=16)$ were associated with a $25 \%$ (n=4) 30-day mortality.

Conclusions: Minimally invasive surgical approaches for AVV disease are increasingly being recognized as the "gold-standard" in the context of rapidly expanding trans-catheter technology and increasing patient expectations. In an era of strict quality control and clinical governance, emerging MIAS centres need to be aware of the possible intra-operative complications and potential pitfalls to apply effective risk reduction strategies that encourage safe and sustainable programs.

Keywords: Minimally invasive valve surgery; quality control; outcomes

Received: 12 June 2018; Accepted: 07 December 2018; Published: 20 December 2018.

doi: 10.21037 /jovs.2018.12.07

View this article at: http://dx.doi.org/10.21037/jovs.2018.12.07 


\section{Introduction}

The current evolution in trans-catheter atrioventricular valve (AVV) repair- and replacement technology (1-3) is paralleled by extensive industry driven marketing (4) and increasing patient expectations (5) that potentially favour catheter-based approaches above surgical options (6). Subsequently, the contemporary role of conventional sternotomy approach (CSA) and even minimally invasive AVV surgery approaches are continuously being redefined. It is now generally accepted that current and future cardiac surgeons need to acquire minimally invasive and interventional skills to strengthen our positions in the future treatment of AVV disease (7-9). Minimally invasive AVV surgery that utilizes endoaortic balloon occlusion (EABO) technology (MIAS, also known as Port Access ${ }^{\mathrm{TM}}$ Surgery), is associated with extensive learning curves, which in a current era of strict quality control and accountability (10), clinical governance $(11,12)$ and an increasing patient risk profile (13), may deter emerging centres from incorporating MIAS into their clinical practice. The intention of this manuscript is to provide an in-depth overview of intraoperative complications and the reasons for sternotomy conversion (SC) associated with MIAS and to outline the potential pitfalls that may assist in the development of safe, efficient and sustainable programs.

\section{Methods}

We performed a retrospective study of a single-centre prospective MIAS database, in which the complication, reasons for SCs and the incidence of intra-operative major adverse cardiac and cerebrovascular events (MACCE) that occurred over the last 5 years were evaluated. The impact of SC on 30-day mortality were also evaluated. In total, 511 consecutive patients that required AVV interventions between May $1^{\text {st }} 2013$ and April 30 $0^{\text {th }}$ 2018, underwent MIAS without exclusion criteria at our institution by our current surgical team. The study was approved by the institutional ethics review committee and all authors accept responsibility for data integrity and the manuscript as written.

\section{Patient selection and work-up}

The indication for MIAS has expanded in experience centres to include isolated AVV disease in primary (14-16) and redo-cardiac surgery $(17,18)$, cryo-ablation for atrial fibrillation (19) and intra-cardiac neoplastic resection (20).
The relevant preoperative patient characteristics, AVV pathology and surgical indications are outlined in Table 1. The mean body mass index (BMI), mean and median logistic EuroSCORE were $25.7 \pm 4.5 \mathrm{~kg} / \mathrm{m}^{2}$ (range, $15.2-45.0 \mathrm{~kg} / \mathrm{m}^{2}$ ), $10.0 \% \pm 13.4 \%$ (range, $1.2-98.0 \%$ ) and $5.2 \%$ respectively. In total, 600 surgically correctable AVV abnormalities were diagnosed in the 511 consecutive patients.

\section{Pre-operative preparation}

We routinely perform pre-operative aorta-iliac-femoralaxis (AIFA) evaluation in all patients either during coronary catheterization or by magnetic resonance angiography. Computerized tomography is not routinely utilized in redo-surgery and no special investigations are performed to evaluate the presence of lung adhesions in patients with previous right hemithorax interventions. All patients are offered the option of MIAS with the intention to treat. Routine cardiac surgical workup is followed by an elaborate informed consent process, which also include the possibility of SC, after which the patient selects a preferred treatment pathway.

\section{Equipment preference card}

The IntraClude device (Edwards Lifesciences, Irvine, California, USA) is a composite EABO device $(10.5 \mathrm{Fr}$, $100 \mathrm{~cm}$ length) that facilitates antegrade cardioplegia delivery, aortic root venting and aortic root pressure monitoring (Figure 1). It is inserted over a guidewire through a Y-arm of the EndoReturn (21-23 Fr, Edwards Lifesciences, Irvine, California, USA) femoral arterial cannula and advanced to the aortic sino-tubular junction. The safety and efficiency of current port access surgery (PAS) technology compared to other clamping strategies are well described (21). The QuickDraw femoral venous cannula (22-25 Fr, Edwards Lifesciences, Irvine, California, USA) is used for venous drainage and is also compatible with percutaneous approaches. Right internal jugular cannulation (16-18 Fr, Optisite $^{\mathrm{TM}}$, Edwards Lifesciences, Irvine, California, USA) augments venous drainage. Single, long shafted instruments facilitate routine and advanced AVV procedures through endoscopic working ports.

\section{Procedure outline}

Our routine techniques are well described (14-20) and a total of 3,072 patients underwent MIAS at our institution 
Table 1 Pre-operative patient characteristics and valve pathology $(\mathrm{n}=511)$

\begin{tabular}{|c|c|}
\hline Patient characteristics & Value \\
\hline Age, mean \pm SD (range) (years) & $65.6 \pm 13.7(17.5-92.7)$ \\
\hline Age above 80 years, $\mathrm{n}(\%)$ & $61(11.9)$ \\
\hline Female, n (\%) & $239(46.8)$ \\
\hline $\begin{array}{l}\text { Body mass index, mean } \pm \text { SD } \\
\text { (range) }\left(\mathrm{kg} / \mathrm{m}^{2}\right)\end{array}$ & $25.7 \pm 4.5(15.2-45.0)$ \\
\hline Above 30 kg/m², n (\%) & $71(13.9)$ \\
\hline Previous cardiac surgery, n (\%) & $111(21.7)$ \\
\hline Previous MI-PAS, n (\%) & $29(5.7)$ \\
\hline \multicolumn{2}{|l|}{ Pre-operative state, n (\%) } \\
\hline Elective & $459(89.8)$ \\
\hline Urgent/emergency & $52(10.2)$ \\
\hline $\begin{array}{l}\text { Mean logistical EuroSCORE } \\
\text { (range) (\%) }\end{array}$ & $10.0 \pm 13.4(1.02-98.0)$ \\
\hline Mean EuroSCORE II (range) (\%) & $5.9 \pm 9.4(0.5-76.8)$ \\
\hline Active endocarditis, n (\%) & $15(2.9)$ \\
\hline $\begin{array}{l}\text { Left ventricle ejection fraction } \\
<30 \%, \mathrm{n}(\%)\end{array}$ & $17(3.3)$ \\
\hline Neurological dysfunction, n (\%) & $20(3.9)$ \\
\hline Poor mobility, n (\%) & $24(4.7)$ \\
\hline Renal dysfunction, n (\%) & $332(65.0)$ \\
\hline COPD, n (\%) & $38(7.4)$ \\
\hline Extra-cardiac arteriopathy, n (\%) & $94(18.4)$ \\
\hline \multicolumn{2}{|l|}{$\begin{array}{l}\text { Atrioventricular valve pathology } \\
(\mathrm{n}=600), \mathrm{n}(\%)\end{array}$} \\
\hline Annular dilatation & $198(33.0)$ \\
\hline Degenerative/sclerotic disease & $285(47.5)$ \\
\hline Rheumatic disease & $33(5.5)$ \\
\hline Congenital abnormalities & $5(0.8)$ \\
\hline Endocarditis (acute/chronic) & $20(3.3)$ \\
\hline Native & $17(2.8)$ \\
\hline Prosthetic & $3(0.5)$ \\
\hline Ischaemic valvulopathy & $4(0.7)$ \\
\hline Prosthetic valve thrombosis & $1(0.2)$ \\
\hline Prosthetic valve paravalvular leak & $5(0.8)$ \\
\hline Prosthetic valve dysfunction & $1(0.2)$ \\
\hline Trauma & $6(1.0)$ \\
\hline Other & $42(7.0)$ \\
\hline
\end{tabular}

SD, standard deviation; MI-PAS, minimally invasive port access surgery; COPD, chronic obstructive pulmonary disease.

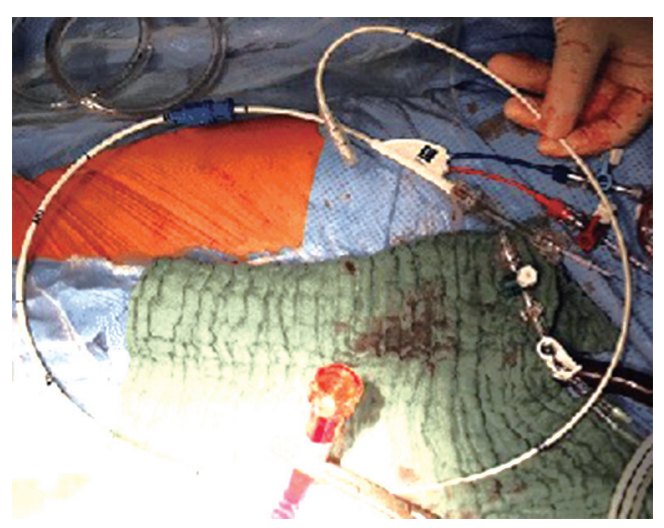

Figure 1 Intraclude ${ }^{\mathrm{TM}}$ endo-aortic balloon occlusion device.

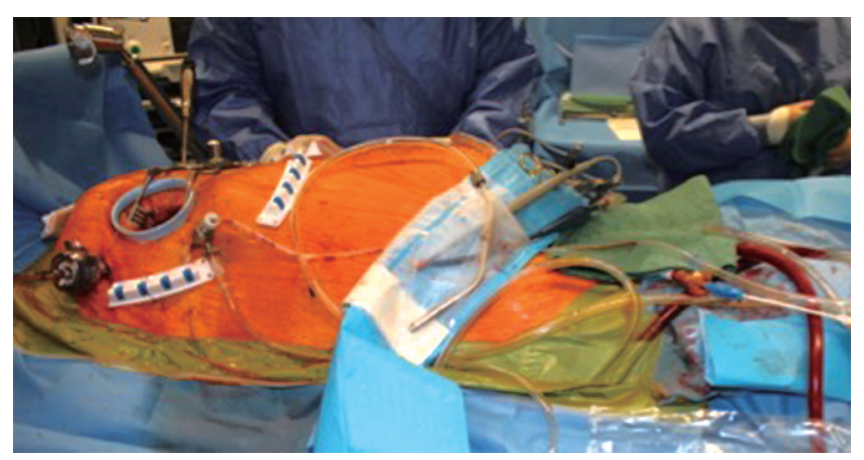

Figure 2 Port Access ${ }^{\mathrm{TM}}$ Surgery in extreme obesity.

up to date. All guidewire advancement and cannulation are established under transoesophageal echocardiography (TEE) guidance, with venous cannulation performed first using standard inferior vena cava and bi-caval TEE views. Femoral artery cannulation and subsequent endo-balloon advancement are guided by standard TEE images of the descending aorta, aortic arch, ascending aorta, sino-tubular junction and aortic root.

A 4-cm non-rib-spreading working port incision is established over the $4^{\text {th }}$ anterior-axillary intercostal space. In extreme obese patients (22), we utilise an endoscopic nonrib-spreading access site soft tissue retractor (SurgiSleeve ${ }^{\mathrm{TM}}$, 2.5-6 cm, Covidien, Massachusetts, USA) for additional wound protection, extra-long (53 or $100 \mathrm{~mm}$ ) endoscopic camera trocars (Vectec SA, Hauterive, France) and establish all intercostal ports by blunt dissection (Figure 2). Unobstructed visual- and working access are ascertained by resecting excessive pericardial fat and retracting the diaphragmatic dome infero-laterally with exteriorized traction sutures. 


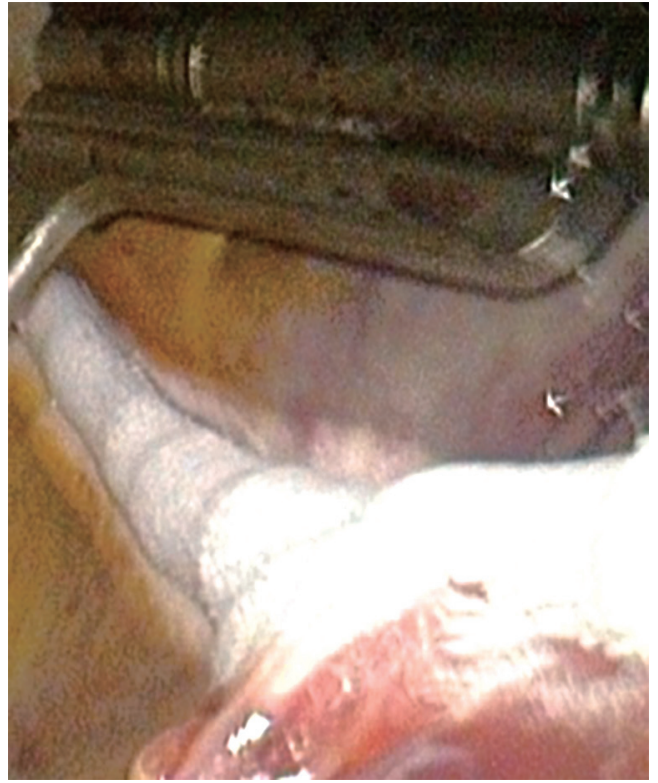

Figure 3 Endoscopic Port Access ${ }^{\mathrm{TM}}$ cryo-ablation.

For difficult access congenital chest wall deformities (23), an adequate working angle and adequate AVV access are the most demanding technical challenges. We routinely position our atrial retractor in the right parasternal zone, lateral to the $4^{\text {th }}$ intercostal space internal mammary bundle, but in cases of pronounced pectus excavatum deformities, the retractor may be positioned on the left parasternal border. The limited antero-posterior retraction distance between the right atrium and anterior chest wall may require tilting the patient maximally to the left while applying low positive end-expiratory pressure (PEEP) to the left lung. Exteriorized stay sutures are utilized to obtain tricuspid valve (TV) exposure, instrument access and adequate working angles in cases of unsuccessful right atrial retraction.

Argon-gas cryo-ablation (Medtronic, Minneapolis, USA) and left atrial appendage closure are performed in patients with atrial fibrillation or previous stroke (Figure 3). Patent foramen ovale are routinely closed and post-procedural de-airing performed by left atrial- and aortic balloon venting catheters, continuous flooding of the operative field with $\mathrm{CO}_{2}$ and TEE evaluation for residual air in the left ventricle.

For access to the left ventricle outflow tract (24), segment $\mathrm{A} 1-\mathrm{A} 3$ of the $\mathrm{MV}$ are detached from the annulus. Following careful septal myomectomy by sharp resection, the $M V$ is augmented with an oversized bovine pericardial
Table 2 Procedures performed, cardiopulmonary bypass and ischaemic times $(\mathrm{n}=600)$

\begin{tabular}{|c|c|}
\hline Variables & Value \\
\hline \multicolumn{2}{|l|}{$\begin{array}{l}\text { Valve procedures performed }(n=600) \\
n(\% \text { of } 600)\end{array}$} \\
\hline Mitral valve procedures & $488(81.3)$ \\
\hline Replacement & $105(17.5)$ \\
\hline Mechanical prosthesis & $30(5.2)$ \\
\hline Biological prosthesis & $75(12.5)$ \\
\hline Valve repair & $383(63.8)$ \\
\hline Tricuspid valve procedures & $112(18.7)$ \\
\hline Replacement (biological prosthesis) & $17(2.8)$ \\
\hline Repair & $95(15.8)$ \\
\hline Isolated mitral valve procedures & 399 (66.5) \\
\hline Isolated tricuspid valve procedures & $23(3.8)$ \\
\hline $\begin{array}{l}\text { Combined mitral and tricuspid valve } \\
\text { procedures }\end{array}$ & $89(14.8)$ \\
\hline \multicolumn{2}{|l|}{$\begin{array}{l}\text { Concomitant cardiac procedures } \\
(n=253 \text { of } 511,49.5 \%), n \text { ( } \% \text { of } 511)\end{array}$} \\
\hline Left ventricle outflow tract resection & $7(1.4)$ \\
\hline Patent foramen ovale closure & $84(16.4)$ \\
\hline Atrial fibrillation ablation & $142(27.8)$ \\
\hline $\begin{array}{l}\text { Hybrid percutaneous coronary } \\
\text { intervention }\end{array}$ & $20(3.9)$ \\
\hline \multicolumn{2}{|l|}{$\begin{array}{l}\text { Cardiopulmonary bypass time, } \\
\text { mean } \pm \text { SD [range] (minutes) }\end{array}$} \\
\hline Isolated MV-surgery & $142 \pm 40[46-314]$ \\
\hline Isolated TV-surgery & $138 \pm 34[76-242]$ \\
\hline Combined MV-TV surgery & $193 \pm 44[118-360]$ \\
\hline Sternotomy conversions (all included) & $207 \pm 102[98-387]$ \\
\hline \multicolumn{2}{|l|}{$\begin{array}{l}\text { Ischaemic time, mean } \pm \mathrm{SD} \\
\text { [range] (minutes) }\end{array}$} \\
\hline Isolated MV-surgery & $96 \pm 30[28-220]$ \\
\hline Isolated TV-surgery & $91 \pm 25[45-162]$ \\
\hline Combined MV-TV surgery & $138 \pm 27[89-214]$ \\
\hline Sternotomy conversions (all included) & $126 \pm 59[55-242]$ \\
\hline
\end{tabular}

SD, standard deviation; MV, mitral valve; TV, tricuspid valve.

patch. Temporary epicardial- or trans-jugular ventricular pacing wires are routinely placed.

The AVV $(n=600)$ and concomitant procedures $(n=253)$ performed by MIAS in 511 consecutive patients between May $1^{\text {st }} 2013$ and April 30 2018 , are outlined in Table 2 and 
Table 3 Intra-operative complications and reasons for sternotomy conversion ( $\mathrm{n}=16)$

\begin{tabular}{lcc}
\hline Reasons for conversion & $\mathrm{N}$ & \% of 511 \\
\hline Early conversions & 9 & 1.8 \\
Lung adhesions & 5 & 1.0 \\
Cannulation difficulty & 4 & 0.8 \\
Guidewire resistance & 3 & 0.6 \\
Aortic dissection & 1 & 0.2 \\
Late conversions & 7 & 1.4 \\
Bleeding & 4 & 0.8 \\
Ventricle perforation & 1 & 0.2 \\
Atrial bleeding & 3 & 0.6 \\
Endo-aortic balloon rupture & 1 & 0.2 \\
Atrio-ventricular dehiscence & 1 & 0.2 \\
Aortic valve injury & 1 & 0.2 \\
Total conversion rates & 16 & 3.1 \\
\hline
\end{tabular}

Table 4 Intra-operative major adverse cardiac and cerebrovascular events (MACCE)

\begin{tabular}{ll}
\hline MACCE & Value \\
\hline $\begin{array}{l}\text { Intra-operative MACCE for total series } \\
(\mathrm{n}=511), \mathrm{n}(\% \text { of } 511)\end{array}$ & $2(0.4)$ \\
$\quad$ Cardiac death & $1(0.2)$ \\
Acute myocardial infarction & $7(1.4)$ \\
Congestive heart failure & $6(1.2)$ \\
Stroke & \\
Intra-operative MACCE for conversions \\
( $=16), \mathrm{n}$ (\% of 16) \\
Cardiac death \\
Acute myocardial infarction \\
Congestive heart failure & $1(6.3)$ \\
Stroke & $0(0)$ \\
\end{tabular}

consisted of $399(66.5 \%), 23(3.8 \%)$ and $89(14.8 \%)$ isolated $\mathrm{MV}$, isolated $\mathrm{TV}$ and combined $\mathrm{MV}$ and $\mathrm{TV}$ procedures respectively. MV-repair was achieved in $97.0 \%(n=324$ of 334) of primary annular dilatation and degenerative valves. The mean cardiopulmonary bypass $(\mathrm{CPB})$ and ischemic times are also described in Table 2.

\section{Role of team members}

We advocate a patient-centred, multi-disciplinary team approach that include cardiologists, experienced anaesthesiologists (25), perfusionists (26), theatre, intensive care, ward and outpatient nurses, physiotherapists, other allied health care professionals, the patient family and referring physicians. Intra-operative communication is essential and each expert opinion should be respected and considered during the procedure. Post-operative intensive care is coordinated by a team of full-time on-site cardiac intensivists, which is followed by a structured and individualized in-hospital multi-disciplinary rehabilitation program. Continuation of care is ascertained by the referring physician as part of patient centred service delivery.

\section{Post-operative management}

Cardio-respiratory support, sedation and analgesia are administered as indicated in intensive care and a structured in-hospital rehabilitation program initiated as soon as possible. All patients undergo pre-discharge trans-thoracic echocardiographic evaluation for satisfactory operative result confirmation. Infective endocarditis is treated with appropriate antibiotics for 6 weeks under the supervision of an infective endocarditis team and long-term anticoagulation regimes initiated and stabilized in-hospital in cases of mechanical prosthetic implantation or chronic atrial fibrillation. All patients are reviewed within 6 weeks postdischarge, after which continuation of care is ascertained by the referring cardiologist and family physician.

\section{Results}

Adverse early and late intra-operative events that required SC occurred in $16(3.1 \%)$ patients. SC that occurred prior to $\mathrm{EABO}$ device inflation are considered "risk aversion strategy changes" or early conversions, whereas late conversions are defined as conversions during or after EABO inflation. The reasons for SC are outlined in Table 3 and included lung adhesions $(\mathrm{n}=5,1.0 \%)$ and cannulation difficulty $(n=4,0.8 \%)$. Peri-operative neurological deficit occurred in $2(0.4 \%)$ patients. Other peri-operative MACCE are outlined in Table 4. The intra-operative and 30 -day mortality for the total series $(\mathrm{n}=511)$ was $0.4 \%(\mathrm{n}=2)$ and $4.5 \%(\mathrm{n}=23)$ respectively.

\section{The impact of intraoperative complications on intraoperative and 30-day mortality}

The 30-day and total in-hospital mortality associated with 
SC for peri-operative complications $(n=16)$ was $25.0 \%(n=4)$.

\section{Tips, tricks and pitfalls}

MIAS is associated with extensive learning curves and in an era where surgical volume is progressively decreasing, emerging centres should be cautious of offering MIAS as a routine to patients with difficult right hemithorax or AVV access (previous right thoracotomy, lung adhesions, radiation therapy, obesity or chest wall deformities), high risk and frail patients, peripheral vascular disease, severely calcified AVV annuli and AVV pathology that require complex repair or replacement techniques. With experience, patient selection may expand to include difficult access extreme obese patients (22), congenital chest wall deformities (23), redo-cardiac surgery (17), redo-MIAS after previous MIAS (18), MIAS in the context of previous orthotopic cardiac transplant (27), complex isolated AVV endocarditis (28), left ventricle outflow tract obstruction with associated AVV disease (24), giant atrial myxoma resection (29) and other complex MIAS procedures (30).

Lung adhesions accounted for $5(31.3 \%)$ of SC $(n=16)$, which occurred in the context of primary $(\mathrm{n}=400,78.3 \%)$, redo-cardiac $(\mathrm{n}=111,21.7 \%)$ and redo-MIAS $(\mathrm{n}=29,5.7 \%)$ procedures. Previous right hemi-thorax interventions are not considered contra-indications in experiences centres and we do not routinely perform any special imaging investigations to identify lung adhesions. Computerized tomography is considered to be of value in redo-cardiac surgery where patent coronary artery bypass grafts are documented and the graft positions are of interest. Targeted access to the valves is obtained by careful release of anterior, mediastinal and diaphragm adhesions by combination of blunt and sharp dissection without causing pulmonary tears or bleeding. In the unlikely event of pulmonary injury, we advocate suture repair prior to initiating systemic anticoagulation.

We prefer a 4-cm right groin incision over the skin-line that facilitates the exposure of the anterior surfaces of the right common femoral artery and vein while avoiding the medial lymphatic regions. Total percutaneous cannulation using vascular closure devices can be performed as a favourable alternative. A low threshold to convert single to bilateral femoral artery cannulation in cases of high $\mathrm{CPB}$ and perfusion pressures should be respected. Routine preoperative AIFA evaluation is mandatory in all patients either during coronary catheterization or by magnetic resonance angiography. Peripheral vascular diameters less than $7 \mathrm{~mm}$, extensive common femoral artery anterior surface or diffuse AIFA calcification, previous common femoral artery interposition grafts, severe central and peripheral vascular tortuosity and ascending aorta diameter more than $4.0 \mathrm{~mm}$ should be approached with extreme caution.

TEE surveillance of controlled and smooth guidewire advancements and peripheral device placements is a prerequisite for safe and sustainable MIAS $(31,32)$. The identification of any resistance or abnormal tactile feedback while advancing guidewires are warnings of potential complications and attempts to force any guidewire or device is strongly discouraged. Cannulation challenges that required SC occurred in $4(0.8 \%)$ patients and included the early identification of guidewire advancement resistance $(\mathrm{n}=3,0.6 \%)$, with aortic dissection occurring in $1(0.2 \%)$ patient.

It is suggested that a pre-selected team under surgical leadership undergo training at an established MIAS centre and practice their operative steps in a simulation or "drylab" setting before performing the first 20 cases (33). It is imperative that all team members are comfortable with the procedure and aware of the potential pitfalls. Frequent postoperative team de-briefing sessions is advised to identify improvement strategies and to reinforce ownership of each team member under the surgical leadership.

All MIAS procedures are prepared, cleaned- and draped according to routine sternotomy access principles and a sternotomy saw should always be immediately available to ensure rapid SC if required. The adjustment of the procedure from MIAS to sternotomy should be conducted in a systematic and organised manner.

Aortic valve injury $(\mathrm{n}=1,0.2 \%)$ and $\mathrm{EABO}$ device rupture by suture puncture $(n=1,0.2 \%)$ occurred due to postinflation migration of the device into the non-coronary sinus. The device positioning is subjected to retrograde $\mathrm{CPB}$ flow pressures and intrinsic device tension and should therefore be locked against the arterial Y-connecting inflow cannula. It can be avoided by careful initial TEE guided placement at the sino-tubular junction, TEE confirmation of its position prior to left atriotomy and careful annular suture placement between the antero-lateral commissure and the A2 segment. We advocate only partial inflation to approximately $75 \%$ of the volume of the ascending aorta in conjunction with the administration of adenosine $(0.25 \mathrm{mg} / \mathrm{kg})$ as a syringe-flush to achieve rapid diastolic cardiac arrest before full inflation and positioning under TEE guidance. Loss of right radial artery pressure indicates cranial EABO migration that obstructs the innominate 
artery and should be corrected immediately.

Bleeding accounted for $4(0.8 \%)$ of SC, which included pacemaker placement related left ventricle perforation $(\mathrm{n}=1,0.2 \%)$ and atriotomy bleeding $(\mathrm{n}=3,0.6 \%)$. The right atrium is closed by two running sutures and the left atrium by single layer. We recommend temporary pacemaker placement on the diaphragmatic aspect of the muscular left ventricle, which is considered to be of lower bleeding risk compared to the right ventricle. All working ports and incisions should be endoscopically controlled for bleeding prior to closure.

Atrio-ventricular dehiscence occurred in $1(0.2 \%)$ patient, which was controlled by valve re-implantation following an uneventful SC. Severe posterior annular calcification can be identified by routine pre-operative imaging and should be resected with extreme caution (34).

\section{Conclusions}

The application of MIAS are continuously evolving in the context of rapidly expanding catheter-based technology and increasing patient expectations. Awareness of pitfalls, reasons for SC and other adverse intra-operative events are imperative to applying effective risk reduction strategies that potentially assist in developing safe and sustainable programs.

\section{Acknowledgments}

Funding: None.

\section{Footnote}

Provenance and Peer Review: This article was commissioned by the Guest Editor (Peyman Sardari Nia) for the series "Minimally Invasive Mitral Valve Surgery" published in Journal of Visualized Surgery. The article has undergone external peer review.

Conflicts of Interest: All authors have completed the ICMJE uniform disclosure form (available at http://dx.doi. org/10.21037/jovs.2018.12.07). The series "Minimally Invasive Mitral Valve Surgery" was commissioned by the editorial office without any funding or sponsorship. FVP reports personal fees from Edwards, during the conduct of the study; personal fees from Edwards, outside the submitted work. The authors have no other conflicts of interest to declare.
Ethical Statement: The authors are accountable for all aspects of the work in ensuring that questions related to the accuracy or integrity of any part of the work are appropriately investigated and resolved. The study was conducted in accordance with the Declaration of Helsinki (as revised in 2013). The study was approved by the institutional ethics review committee (ID: B126201627171). Individual informed consent was waived due to the retrospective nature of the study.

Open Access Statement: This is an Open Access article distributed in accordance with the Creative Commons Attribution-NonCommercial-NoDerivs 4.0 International License (CC BY-NC-ND 4.0), which permits the noncommercial replication and distribution of the article with the strict proviso that no changes or edits are made and the original work is properly cited (including links to both the formal publication through the relevant DOI and the license). See: https://creativecommons.org/licenses/by-nc-nd/4.0/.

\section{References}

1. Rosengart TK, Feldman T, Borger MA, et al. Percutaneous and minimally invasive valve procedures: a scientific statement from the American Heart Association Council on Cardiovascular Surgery and Anaesthesia, Council on Clinical Cardiology, Functional Genomics and Translational Biology Interdisciplinary Working Group, and Quality of Care and Outcomes Research Interdisciplinary Working Group. Circulation 2008;117:1750-67.

2. Masson JB, Webb JG. Percutaneous treatment of mitral regurgitation. Circ Cardiovasc Interv 2009;2:140-6.

3. Mylotte D, Piazza N. Transcatheter mitral valve implantation: a brief review. EuroIntervention 2015;11 Suppl W:W67-70.

4. Ferraris VA, Ferraris SP. assessing the medical literature: let the buyer beware. Ann Thorac Surg 2003;76:4-11.

5. Tully PJ, Baker RA, Turnbull DA, et al, Negative emotions and quality of life six months after cardiac surgery: the dominant role of depression not anxiety symptoms. J Behav Med 2009;32:510-22.

6. Mack M. Fool me once, shame on you; fool me twice, shame on me! A perspective on the emerging world of percutaneous heart valve therapy. J thorac Cardiovasc Surg 2008;136:816-9.

7. Bouhout I, Morgant MC, Bouchard D. Minimally Invasive 
Heart Valve Surgery. Can J Cardiol 2017;33:1129-37.

8. Doenst T, Lamelas J. Do we have enough evidence for minimally-invasive cardiac surgery? A critical review of scientific and non-scientific information. J Cardiovasc Surg (Torino) 2017;58:613-23.

9. Bertrand $X$. The future of cardiac surgery: find opportunity in change! Eur J Cardiothorac Surg 2013;43:253-4.

10. Seder CW, Raymond DP, Wright CD, et al. The Society of Thoracic Surgeons General Thoracic Surgery Database 2017 Update on Outcomes and Quality. Ann Thorac Surg 2017;103:1378-83.

11. Schneider EC, Epstein AM. Use of public performance reports: a survey of patients undergoing cardiac surgery. JAMA 1998;279:1638-42.

12. Jacobs JP, Certfolio RF, Sade RM. The ethics of transparency: publication of cardiothoracic surgical outcomes in the lay press. Ann Thorac Surg 2009;87:679-86.

13. Iung $B$, Baron $G$, Butchart EG, et al. A prospective survey of patients with valvular heart disease in Europe: the Euro Heart Survey on Valvular Heart Disease. Eur Heart J 2003;24:1231-43.

14. Casselman FP, Van Slycke S, Dom H, et al. Endoscopic mitral valve repair: feasible, reproducible, and durable. J Thorac Cardiovasc Surg 2003;125:273-82.

15. Casselman FP, Van Slycke S, Wellens F, et al. From classical sternotomy to truly endoscopic mitral valve surgery: a step by step procedure. Heart Lung Circ 2003;12:172-7.

16. Casselman FP, Van Slycke S, Wellens F, et al. Mitral valve surgery can now routinely be performed endoscopically. Circulation 2003;108:II48-54.

17. Casselman FP, LaMeir M, Jeanmart H, et al. Endoscopic mitral and tricuspid valve surgery after previous cardiac surgery. Circulation 2007;116:1270-5.

18. van der Merwe J, Casselman F, Stockman B, et al. Late redo-port access surgery after port access surgery. Interact Cardiovasc Thorac Surg 2016;22:13-8.

19. Jeanmart H, Casselman F, Beelen R, et al. Modified maze during endoscopic mitral valve surgery: the OLV Clinic experience. Ann Thorac Surg 2006;82:1765-9.

20. Deshpande RP, Casselman F, Bakir I, et al. Endoscopic cardiac tumor resection. Ann Thorac Surg 2007;83:2142-6.

21. Casselman F, Aramendi J, Bentala M, et al. Endoaortic Clamping Does Not Increase the Risk of Stroke in Minimal Access Mitral Valve Surgery: A Multicenter Experience. Ann Thorac Surg 2015;100:1334-9.

22. Van der Merwe J, Casselman F, Stockman B, et al. Endoscopic atrioventricular valve surgery in extreme obesity. Türk Gögüs Kalp Damar Cerrahisi Dergisi 2017;25:654-8.

23. van der Merwe J, Casselman F, Stockman B, et al. Endoscopic atrioventricular valve surgery in adults with difficult-toaccess uncorrected congenital chest wall deformities. Interact Cardiovasc Thorac Surg 2016;23:851-5.

24. Casselman F, Vanermen H. Idiopathic hypertrophic subaortic stenosis can be treated endoscopically. J Thorac Cardiovasc Surg 2002;124:1248-9.

25. Coddens J, Deloof T, Hendrickx J, et al. Transesophageal echocardiography for port-access surgery. J Cardiothorac Vasc Anesth 1999;13:614-22.

26. Gooris T, Van Vaerenbergh G, Coddens J, et al. Perfusion techniques for port-access surgery. Perfusion 1998;13:243-7.

27. van der Merwe J, Casselman F, Stockman B, et al. Endoscopic Port Access ${ }^{\mathrm{TM}}$ Surgery for Late Orthotopic Cardiac Transplantation Atrioventricular Valve Disease. J Heart Valve Dis 2017;26:124-9.

28. van der Merwe J, Casselman F, Stockman B, et al. Endoscopic port access surgery for isolated atrioventricular valve endocarditis. Interact Cardiovasc Thorac Surg 2018;27:487-93.

29. van der Merwe J, Casselman F, Van Praet F. Endoscopic Port Access ${ }^{\mathrm{TM}}$ Resection of a massive Atrial Myxoma. SA Heart Journal 2016;13:302-3.

30. van der Merwe J, Beelen R, Martens S, et al. Single-Stage Minimally Invasive Surgery for Synchronous Primary Pulmonary Adenocarcinoma and Left Atrial Myxoma. Ann Thorac Surg 2015;100:2352-4.

31. Jeanmart H, Casselman FP, De Grieck Y, et al. Avoiding vascular complications during minimally invasive, totally endoscopic intra-cardiac surgery. J Thorac Cardiovasc Surg 2007;133:1066-70.

32. van der Merwe J, Casselman F, Beelen R, et al. Total Percutaneous Cardiopulmonary Bypass for Robotic- and Endoscopic Atrioventricular Valve Surgery. Innovations (Phila) 2017;12:296-9.

33. Hunter $\mathrm{S}$. How to start a minimal access mitral valve program. Ann Cardiothorac Surg 2013;2:774-8.

34. Uchimuro T, Fukui T, Shimizu A, et al. Mitral Valve Surgery in Patients With Severe Mitral Annular Calcification. Ann Thorac Surg 2016;101:889-95.

doi: 10.21037 /jovs.2018.12.07

Cite this article as: van der Merwe J, Van Praet F, Vermeulen Y, Casselman F. Complications and pitfalls in minimally invasive atrioventricular valve surgery utilizing endo-aortic balloon occlusion technology. J Vis Surg 2018;4:248. 